\title{
La construcción del discurso político del emprendimiento en España. Realidad e ideología
}

\author{
Pilar Ortiz García
}

Universidad de Murcia. Departamento de Sociología

potizg@um.es

Recepción: 29-09-2016

Aceptación: 13-02-2017

\section{Resumen}

El objetivo de este artículo es conocer las claves que conforman el discurso parlamentario sobre el emprendimiento. La hipótesis de partida es que existe una construcción institucional de dicho discurso marcada por las distintas posiciones ideológicas de los grupos parlamentarios y por su posición respecto al Gobierno de la nación. Para ello se ha utilizado la metodología cualitativa de análisis de discurso, con la que se han estudiado las intervenciones de los parlamentarios recogidas en el Diario de Sesiones del Congreso de los Diputados en las legislaturas VIII, IX y X en España. Los resultados de la investigación muestran que la posición del Gobierno determina un discurso hegemónico que otorga un significado al emprendimiento cuyas claves son el énfasis en la responsabilidad del individuo en el crecimiento económico y la superación de la crisis; la identificación del emprendimiento con la consecución de objetivos sociales — una retórica con la que se consigue «neutralizar»el discurso crítico de la oposición-y la reiteración persuasiva, que proyecta en la sociedad una imagen que no se corresponde con la realidad del emprendimiento en España.

Palabras clave: emprendedor; Gobierno; política; economía; legislatura

\section{Abstract. Analysis of political speeches on entrepreneurship in Spain: Reality and ideology}

The aim of this article is to determine the key elements of parliamentary discourse on entrepreneurship in Spain. We hypothesize that the institutional construction of discourse is marked by the different ideological positions of the parliamentary groups and their position with respect to the national government. To achieve this goal, we have used a qualitative discourse analysis methodology to study the interventions of members of the lower house of parliament published in the Journal of Sessions of the Congress of Deputies (Diario de Sesiones del Congreso de los Diputados) in the VIII, IX and X legislatures in Spain. The results show that the government's position determines a hegemonic discourse whose key elements place emphasis on individual responsibility for economic growth and to overcome the crisis, associate entrepreneurship with social goals-a rhetoric which seeks to "neutralize" the critical discourse of the opposition — and persuasive repetition, which projects an image to society that does not correspond to the reality of entrepreneurship in Spain.

Keywords: entrepreneur; government; politics; economy; legislature 


\begin{aligned} & \multicolumn{2}{c}{ Sumario } \\ & 1. Introducción 4. Metodología \\ & $\begin{aligned} \text { 2. Marco teórico: el discurso sobre el } & \text { 5. Resultados } \\ \text { emprendimiento como argumento } & \text { 6. Conclusiones } \\ \text { ideológico } & \text { Referencias bibliográficas }\end{aligned} \\ & \begin{aligned} \text { 3. La realidad del emprendimiento } & \end{aligned}\end{aligned}$
en España

\section{Introducción}

La dispersión semántica en torno al concepto de emprendedor es amplia, ello hace necesaria una breve introducción que contribuya a aclarar el objeto a que se referirá este artículo. Dicha dispersión tiene su origen en las distintas concepciones sobre esta figura y el fenómeno que desencadena su actividad (Ararat, 2010). La literatura sobre el tema alude, por una parte, a una concepción económica del hecho emprendedor que entronca con la tesis schumpeteriana (1957). Para esta línea teórica, el emprendedor es el motor del desarrollo económico y, como tal, es el impulsor del progreso social a partir de la innovación constante. La segunda acepción es la psicológica, cuyo desarrollo teórico está centrado en el individuo. Esta perspectiva analiza el emprendimiento a partir de las dimensiones del comportamiento y los rasgos personales que permiten identificar esta figura (McClelland, 1961).

Por último, desde una perspectiva sociológica, se concibe el fenómeno emprendedor como la manifestación del cambio social y de la integración de las fuerzas económicas y sociales. Esta línea — de raíces weberianas ${ }^{1}$ - ha sido una de las menos exploradas. No obstante, a partir de los años ochenta emergen un conjunto de estudios académicos sobre el tema desde muy diversas vertientes. Algunas de estas investigaciones han analizado la influencia de la movilidad, tanto social como geográfica, en la propensión al emprendimiento (Hagen, 1968). Otros estudios combinan factores de personalidad con aspectos sociales, tales como la disponibilidad de recursos económicos o personales, como es la existencia de redes sociales (Gibb y Ritchie, 1982; Ajzen, 1988; Burt, 2000). Finalmente, algunos trabajos relativizan la determinación del empresario en la acepción schumpeteriana del término (como actor individual, visionario e intuitivo), para enfatizar en el hecho emprendedor como una combinación de factores que operan a largo plazo (Giraudeau, 2007). No obstante, la perspectiva sociológica no ha sido una de las más trabajadas, lo que ha propiciado un tratamiento del tema de forma «asocial» $\mathrm{y}$ «atemporal»

1. En la Ética protestante y el espiritu del capitalismo (Weber, 1999: 69) se puede identificar la figura del emprendedor en la burguesía de ética calvinista que protagoniza las iniciativas empresariales de «nuevo estilo». Una ética que «encarna cualidades éticas específicas», como son la «racionalidad», la «firmeza de carácter», la «clara visión» y la "capacidad de acción», atributos todos ellos que no han perdido vigencia en la definición de esta figura. 
(Pereira, 2007: 19), de ahí la oportunidad de los estudios que adoptan esta perspectiva.

La débil línea trazada entre lo que se conceptualiza como emprendimiento y empresa o emprendedor y empresario se ha puesto de manifiesto por autores que, como Veciana (2005: 34), manifiestan su «perplejidad» ante el cambio lingüístico que desplaza la palabra empresario en pro de la utilización del concepto de emprendedor. Cabe preguntarse por la diferencia entre ambos términos que, para el autor, es escasa. No obstante, se puede establecer — siguiendo a este mismo autor - que la diferencia estriba en parámetros que tienen que ver con el resultado de la acción. Según esto, el emprendedor sería aquel cuyo resultado de la acción es la creación de una empresa o de nuevos puestos de trabajo, lo que remite a una acepción dinámica del concepto; mientras que el concepto de empresario contendría una acepción estática. En esta dirección, Pereira (2007) indica que lo que da sentido al término emprendedor es el continuo proceso innovador. El movimiento, la búsqueda de oportunidades, la innovación, en definitiva, son los atributos que acompañan al «espíritu emprendedor».

Este significado resulta de especial interés en el análisis del contexto en el que se emplea el término emprendedor y el discurso que se despliega sobre el emprendimiento. La perspectiva sociológica orienta la investigación hacia la construcción de una realidad provista de la dimensión espacio y de la dimensión tiempo. El espacio es el de la economía postfordista, donde la flexibilidad, la estrategia proactiva, la innovación y la activación concurren con una política de impulso a la iniciativa emprendedora (Serrano y Crespo, 2002; Crespo y Serrano, 2013). El tiempo es el de la crisis económica. Se trata de un momento en el que el emprendimiento se constituye en solución ideológica ante la ineficacia de las iniciativas públicas en la crisis del empleo. Desde este punto de vista, el énfasis puesto en el desarrollo del espíritu emprendedor obedecería más a la «subjetividad de juicios y creencias" (Ararat, 2010) que al producto de una realidad en términos de oportunidades y desarrollo de iniciativas que redunden en el desarrollo social y económico, verdadero sentido del reclamado espíritu (García, 2006).

Este artículo tiene como objetivo indagar en la construcción de esta realidad a partir del discurso político en torno al emprendimiento desarrollado en España, coincidiendo con el estallido de la crisis — dimensión temporal- y con la emergencia de políticas flexibles — dimensión espacial—en un mercado de trabajo aquejado de un elevado desempleo.

\section{Marco teórico: el discurso sobre el emprendimiento como argumento ideológico}

El emprendimiento como práctica económica y social ha despertado un gran interés en los últimos años. Su análisis ha inundado los foros económicos, educativos y políticos. Al calor de esta emergencia, en el ámbito académico se han creado cátedras universitarias en cuyo seno se observan y analizan las variables que determinan las tasas de emprendimiento, se explotan los resultados de encuestas de amplia proyección geográfica, como el Global Entrepreneurship 
Monitor (GEM), y se realizan propuestas para incentivar un espíritu emprendedor entre los estudiantes.

La realidad socioeconómica se ha llenado de anglicismos con los que denominar distintas tipologías de emprendedor y de negocio (business angel, startup) o entornos propicios para el emprendimiento (ecosistema emprendedor). Todo ello ha ido gestando la idea de que la actividad emprendedora es la estrategia adecuada para propiciar el desarrollo económico y una acción a impulsar en cualquiera de sus formas. Esta presunción no ha impedido, sin embargo, el desarrollo de algunas tesis críticas sobre lo que supone el emprendimiento y su capacidad para generar riqueza. Resulta difícil discernir entre dos realidades que tienen un mismo fin: el empleo. Una primera realidad es la que lleva a iniciar una actividad animada por las expectativas del mercado: es el emprendimiento motivado por la oportunidad; la otra es la que, desde el pesimismo ante las posibilidades de empleo, lleva al emprendimiento como forma de autoempleo, lo que corresponde a un emprendimiento por necesidad. Desde esta perspectiva, Jones y Spicer (2009: 109) consideran que «el emprendizaje promete la innovación social y la mejora» en un discurso que adolece de problemas éticos, pues lo que hacen es "glorificar una suerte de soberanía individual autista en un mundo en que, debido a la socialización del trabajo, los emprendedores necesitan, más que nunca, a los otros» (Jones y Spicer, 2009: 114).

No obstante, los planteamientos críticos no son predominantes en el análisis del emprendimiento, sino aquellos que enfatizan en las bondades de la actividad y el espíritu que la acompaña, un espíritu a impulsar como exponente de innovación y cambio permanentes.

La introyección social del «espíritu emprendedor» se convierte en una prioridad en las estrategias políticas a través de la educación y el despliegue de actividades que sensibilizan sobre su importancia en el ámbito económico. Las reglas discursivas del nuevo paradigma conectan con las claves del nuevo escenario económico y managerial, en el que, junto a la flexibilidad y el fomento de las iniciativas individuales, el emprendizaje es el nuevo modelo a seguir (Alonso y Fernández, 2011), y la empleabilidad, la alternativa a la crisis de la sociedad salarial (Moruno, 2016).

Este discurso exonera de la responsabilidad de generar actividad económica y empleo a los agentes institucionales y la traslada a una sociedad civil cuyos individuos — generalmente jóvenes — deben asumir la iniciativa emprendedora que lleve al crecimiento y a la riqueza. Individuos innovadores, creativos y flexibles (Gertler y Wolfe, 2002; Gardner, 1995). El corolario de dicha traslación es que el desempleo constituye una consecuencia de la falta de este espíritu o de esta iniciativa emprendedora que, en último extremo, los poderes públicos han de potenciar. Desde esta premisa, no existiría un problema de empleo, sino de falta de emprendedores. El «discurso activador» se ha instalado en las políticas europeas y españolas de orientación para el empleo (Crespo y Serrano, 2013) bajo la premisa de que la potenciación de las competencias del individuo, esto es, «el trabajo sobre uno mismo», conduce al empleo (Serrano et al., 2012). Este paradigma de la activación, sin embargo, no está exento de paradojas, ya que, 
al mismo tiempo que promueve la autonomía y la independencia individual, insta a la supeditación a los dictados del mercado (Santamaría y Serrano, 2016).

Dicha práctica discursiva ha cobrado una especial fuerza en el contexto de la última crisis económica y en el escenario de postcrisis. Las recetas neoliberales sobre recuperación económica apuntan hacia un reducción del papel del Estado, en la convicción de que será la iniciativa privada la que asumirá el protagonismo de la innovación, el crecimiento y el empleo. Este discurso ha sido especialmente contundente entre los políticos conservadores, que animan a emprender una «cruzada» contra los «enemigos de las empresas» ${ }^{2}$. La crisis económica actual ha propiciado de nuevo el debate en torno a la intervención de los poderes públicos en la economía y, al mismo tiempo que se demanda la puesta en marcha de políticas activas de empleo ${ }^{3}$, se la ve como un obstáculo para el desarrollo de la iniciativa privada, especialmente en el escenario político, en el que la gobernabilidad se encuentra mediatizada por la dicotomía entre el espacio público y el privado (Calvo y Lerma, 2009) como representación de los extremos ideológicos socialdemócrata y liberal.

Las prácticas económicas de corte liberal operadas sobre el mercado de trabajo español (Ortiz, 2013, 2014) en los últimos años, configuran el contexto propicio para la emergencia de un discurso en el que el emprendimiento es visto como una salida pragmática a la contracción del mercado laboral.

Como parte del discurso social, el discurso político resulta clave en la configuración de significados construidos ideológica y «persuasivamente», en torno a los cuales se organizan los debates y se genera opinión pública (Guerrero y Vega, 2014). Dicho discurso, que representa una realidad determinada (en este caso, la bondad del emprendimiento como solución a la crisis de empleo), legitima la acción política a la vez que convence y construye la realidad social. Las representaciones sociales que se manejan en el discurso político en torno al emprendimiento simbolizan el crecimiento económico del «moderno» capitalismo "proactivo» frente al que podría denominarse «reactivo», impulsado por la acción de los poderes públicos.

En esta estrategia ideológica resulta interesante analizar la organización del significado, esto es, las redes conceptuales y los modelos de pensamiento que se activan en la construcción del sentido del discurso que busca "modelizar» la praxis social (Charaudeau, 2003). Avanzando en este argumento, se puede decir que, para que la tematización política del emprendimiento tenga los resultados esperados en la práctica social, es importante no solo que los argumentos tengan la suficiente solidez y coherencia, sino que además el discurso se acompañe de elementos persuasivos que legitimen su bondad frente a otros discursos alternativos (Cejudo, 2008). El lenguaje sobre el emprendimien-

2. Mariana Mazzucato, en El Estado emprendedor (2014: 50), recoge esta expresión del primer ministro británico David Cameron en 2011 en alusión a la necesidad de remover los obstáculos de la iniciativa privada, especialmente los que plantean los «burócratas de los departamentos gubernamentales».

3. En cumplimiento de las directrices en política de empleo marcadas por la estrategia Europa 2020 y la Estrategia Europea de Empleo. 
to, connotado positivamente, adquiere una dimensión performativa sobre la acción de los individuos.

El discurso social, modelizado por el discurso político, adopta y normaliza conceptos que han sido ideologizados a partir de redes significantes que dotan de contenido a prácticas, agendas y programas políticos (Guerrero y Vega, 2014). El discurso en torno al emprendimiento forma parte de esta secuencia en la que aparece ligado a los conceptos más genéricos de desarrollo y empleabilidad, dentro de la paulatina consolidación de las políticas de empleo del paradigma de la activación. Ello refuerza el significado de un término que también aparece vinculado a la educación (bajo la premisa de que el emprendedor puede ser "formado», trascendiendo las explicaciones psicologistas sobre el origen del comportamiento de este) o al progreso y la democracia, especialmente en las economías en desarrollo. Esta instrumentalización, ya analizada en realidades diferentes (Vega, 2014; Angenot, 2010), adopta en el escenario económico español el carácter de "oportunidad", a la vez que de condición para alcanzar objetivos socialmente irrenunciables, como es el empleo.

Esta premisa coloca el discurso sobre el emprendimiento en el escenario político como objetivo de gobierno. Ello explicaría que, independientemente de la ideología del partido gobernante, el emprendimiento y las prácticas conducentes a su promoción son "patrimonializadas» por el partido que se encuentra en el poder. La posición de gobierno otorga un papel privilegiado a sus agentes, que disponen de la capacidad para «construir» lo que se considera relevante de la realidad social, de tal forma que el discurso funciona como un mecanismo de reproducción del poder y del «dominio social» (Van Dijk, 1999). Esta premisa orienta el presente estudio. El análisis crítico de discurso ha sido utilizado en investigaciones que buscan desvelar las relaciones de poder o las posiciones ideológicas de sus emisores. Su uso permite revelar dichas relaciones tal como se manifiestan — de forma más o menos explícita- a través del lenguaje (Fairclough y Wodak, 1997). Esta orientación investigadora trasciende el análisis textual para adentrarse en la relación entre lenguaje y sociedad, dejando constancia de las modificaciones en el discurso como parte de procesos de transformación social. Tal como analizaría Fairclough (2002), los cambios en las relaciones de trabajo han venido acompañados de desarrollos discursivos que los legitiman. En este sentido, uno de los ejes que articulan el cambio en las políticas de empleo en un contexto de crisis es la activación de los individuos a partir de la promoción de la empleabilidad y el emprendimiento (Serrano y Crespo, 2002), por lo que el análisis del discurso político que acompaña a dicha estrategia se convierte en un objeto de interés.

\section{La realidad del emprendimiento en España}

El último informe GEM-España 2015 pone de manifiesto que la tasa de actividad emprendedora ${ }^{4}$ (TEA) viene experimentando un moderado crecimiento

4. Esta tasa mide las iniciativas emprendedoras con menos de tres años y medio de vida en el mercado sobre la población de 18 a 64 años. 
desde 2013. En dicho año el TEA fue de un 5,2\%, un año más tarde crecía hasta un 5,5\% y en 2015 subió dos décimas más, situándose en un 5,7\%. Este pequeño crecimiento estuvo motivado principalmente por el incremento de emprendedores nacientes (de 0 a 3 meses). No obstante, España se encuentra por debajo de la media europea (de un 6,9\%).

En cuanto a las características de este emprendimiento, la oportunidad prima sobre la necesidad $\mathrm{u}$ otras razones como motivo para iniciar una actividad (un 73,5\% y un 24,9\% respectivamente en 2015), aunque desde 2009 aumentó el porcentaje de los que decían emprender por necesidad como posible huella de los efectos de la crisis, que ha hecho del emprendimiento una salida para los desempleados. Asimismo, en 2015 se mantiene el perfil eminentemente masculino entre los emprendedores (un 6,4\% de TEA masculina frente a un 5,0\% de TEA femenina). En cuanto al tipo de empresa creada, el emprendimiento ha sido especialmente activo en el sector orientado al consumo (un $51,1 \%$ ) y promovido por una sola persona, si se tiene en cuenta que cinco de cada diez nuevos negocios pertenecen a autoempleados. Se trata de negocios poco competitivos y con escasa innovación y proyección de crecimiento (un 10,6\% representa a iniciativas completamente innovadoras en producto o servicio y un $8,5 \%$ no tienen competencia en su mercado principal). Además, un escaso porcentaje (un 11,9\%) utiliza tecnologías de menos de un año en el mercado o son de base tecnológica media o alta (un 7,9\%). Por último, su capacidad exportadora no es elevada, a la vista de que ocho de cada diez manifiestan no tener vocación internacional durante sus primeros tres o cuatro años de existencia.

Los datos no resultan esperanzadores de cara a impulsar el crecimiento económico. Por otra parte, la encuesta 2015 recoge información sobre los valores y las actitudes emprendedoras de la población. De estos datos se deducen dos aspectos: por una parte, que la intención emprendedora de la población española es muy baja: solo un 6,1\% manifiesta dicha intención en los tres años siguientes (porcentaje que además desciende respecto a 2014, en que era del $8 \%$ ), un hecho significativo teniendo en cuenta que se trata de unos años en los que se atisbaba la recuperación económica. El segundo aspecto destacable es que, si bien el 45,3\% de la población encuestada se considera con habilidades para el emprendimiento, un porcentaje similar a este (un 43,1\%) no lo haría por miedo al fracaso de la experiencia, lo que denota una predisposición poco favorable hacia una actividad que tiene como premisa una dosis importante de riesgo.

Estos datos vienen a corroborar los obtenidos en la encuesta sobre el emprendimiento entre los jóvenes realizada por el Centro de Investigaciones Sociológicas (CIS) en $2012^{5}$, que ratifican su escasa disposición a crear una empresa (el 60\% de los jóvenes no lo ha pensado nunca).

Los esfuerzos institucionales para fomentar la «iniciativa o espíritu emprendedor» cobraron especial importancia en España a partir de la publicación de

5. CIS (2012), Actitudes de la juventud en España hacia el emprendimiento, estudio número 2938 (marzo-abril). 
las directrices europeas ${ }^{6}$, que persiguen dicho objetivo con su introducción en los ámbitos educativo 7 y económico. Desde 1997, la Estrategia Europea de Empleo ha tenido un importante papel en la orientación de las políticas laborales de los estados miembros. En la actualidad, esta iniciativa forma parte de la estrategia de crecimiento Europa 2020. En el caso de España y en el marco de este programa, se han implementado diversas iniciativas de lucha contra el desempleo y/o de promoción de empleo a partir de estrategias que conjuguen la flexibilidad requerida por el actual sistema productivo, con la seguridad propia de un empleo de calidad ${ }^{8}$, especialmente en colectivos vulnerables en el mercado laboral, como son los jóvenes. A estas iniciativas pertenecen la Estrategia de Emprendimiento y Empleo Joven 2013-2016 y el sistema de Garantía Juvenil de 2013, que recoge los planteamientos de la Comisión Europea sobre el tema.

En el ámbito económico la legislación ha sido profusa y, a la norma gene$\mathrm{ral}^{9}$, se suman las reglamentaciones de las comunidades autónomas. La Ley 14/2013 ha despertado algunas controversias en la evaluación de su eficacia, y algunos estudios (Ruiz et al., 2014) evidencian que la acción de los gobiernos - y la legislativa en particular - no es una condición suficiente para la generación de iniciativas emprendedoras. Según Estrin et al. (2013), la estructura de incentivos creada desde los gobiernos no solo determina la elección por emprender o no, sino el tipo de negocio en el que hacerlo. Así pues, iniciativas que pretendan fomentar el autoempleo generarán un emprendimiento de características determinadas, distinto de aquellas que se orienten a potenciar el emprendimiento "estratégico». Por otra parte, puede resultar ineficaz una única estrategia de políticas públicas que no tenga en cuenta las distintas formas de emprendimiento. En este sentido, la conclusión del análisis de Ruiz et al. (2014: 48) es que la Ley 14/2013, al adolecer de esta ausencia de discriminación sobre la heterogeneidad del emprendimiento, ofrece dudas razonables sobre su eficacia.

Este planteamiento resulta de especial interés si se tiene en cuenta que la normativa, en su preámbulo, alude a la oportunidad de la ley ante la grave crisis económica y del empleo - especialmente a la elevada tasa de desempleo juvenil-, una situación que debe ser transformada a través de la educación en el emprendimiento y con una normativa que impulse «ganancias de pro-

6. Dichas directrices están recogidas en enero de 2013 en el Plan de Acción sobre Emprendimiento 2020, del Parlamento Europeo, y que supone una revisión y actualización de la Small Business Act, de abril de 2011.

7. Real Decreto 126/2014, de 28 de febrero; BOE núm. 52, de 1 de marzo de 2014, que establece el currículo básico de la Educación Primaria; Ley Orgánica 10/2002, de 23 de diciembre, de Calidad de la Educación; BOE núm. 307, de 24 de diciembre de 2002, que indica los objetivos a desarrollar en la ESO relacionados con la cultura emprendedora; Ley Orgánica 2/2006, de 3 de mayo, de Educación (LOE), y BOE núm. 106, de 4 de mayo de 2006, que integra la formación en habilidades emprendedoras.

8. Al respecto, es necesario hacer mención de la Comunicación de la Comisión Europea de 2007 sobre flexiguridad.

9. La Ley $14 / 2013$, de 27 de septiembre, de apoyo a los emprendedores y su internacionalización. BOE núm. 233, de 28 de septiembre de 2013. 
ductividad», por lo que, según la tesis expuesta, la ley estaría promoviendo un emprendimiento «reactivo» o de «baja intensidad». Es decir, se legisla sobre el emprendimiento como «reacción» ante el problema del desempleo, no tanto porque constituya el puntal del desarrollo estratégico del país.

\section{Metodología}

El análisis de discurso ha sido el método de carácter cualitativo utilizado para identificar los códigos usados en los textos que han servido de base para analizar el significado del emprendimiento. El análisis ha partido de una perspectiva estructural, según la cual los sistemas semiológicos construyen lo social a través de relatos, textos y discursos (Alonso y Fernández, 2006; Olaz, 2008). Siguiendo esta premisa, en el análisis de discurso se han cumplido los siguientes principios:

1. Principio de formalización. Se trata de reunir relatos para construir una estructura. En este estudio los relatos objeto de análisis son las intervenciones de los representantes de los distintos grupos parlamentarios en los debates de los plenos del Congreso de los Diputados, recogidos en su Diario de Sesiones.

2. Principio de permanencia. Se pretende encontrar las diferencias de forma que vienen atestiguadas por las diferencias de sentido (Barthes, 1990: 288289). En este estudio se ha realizado una búsqueda en los textos a partir de la raíz emprend-, lo que ha permitido registrar las distintas formas derivadas: emprender, emprendedores, emprendedor y emprendimiento.

3. Principio de pluralidad. Este principio se ha cumplido a partir del establecimiento de las variables susceptibles de conferir significados diferentes al término emprendimiento: el grupo parlamentario (se trata de comprobar si la variable ideología es determinante del significado otorgado a emprendimiento); la posición de poder, esto es, si el parlamentario pertenece a un partido político que se encuentra en el gobierno o en la oposición y, por último, la legislatura, en este caso se han analizado las tres últimas: VIII (2004-2008), IX (2008-2011) y X (2011-2015).

4. Disposiciones operativas. Para cumplir este principio, los textos se han trabajado a través del software para el análisis cualitativo de datos ATLAS.ti 7. Ello ha permitido analizar los documentos primarios a varios niveles. En un primer nivel, las herramientas llamadas examinador de palabras, consulta de citas y tabla de coocurrencia han servido para realizar un análisis descriptivo e interpretativo de los textos a partir de la codificación y la categorización de la información, identificando uno o más pasajes de texto con un tema y relacionándolo con el código del concepto descrito. De esta operación han resultado un total de 306 códigos. En un segundo nivel, se ha realizado un análisis relacional a partir de la construcción de «redes semánticas de códigos», lo que ha supuesto el establecimiento de vínculos útiles para conocer las construcciones de significado en torno al emprendimiento. 
Justifican la elección de los discursos parlamentarios de estas tres legislaturas el hecho de que el objeto de este trabajo es indagar sobre cómo se ha construido el discurso en torno al emprendimiento, partiendo de la hipótesis de que la posición institucional o de gobierno es determinante a la hora de conferir significado a este término, unido a los de desarrollo, empleo y salida de la crisis. Esta hipótesis ha sido confirmada en otros estudios que concluyen que, cuando no existe un consenso sobre un significado - como es el caso del emprendimiento-, se convierte en algo impuesto, dictado por la autoridad dominante y naturalizado (mito) (Barthes, 1974). Sin embargo, este mito explicita la ideología dominante, aquella que impone el discurso de quien ostenta una posición que le permite obtener capacidad de difusión.

Por último, la elección de estas tres últimas legislaturas responde a la concurrencia de medidas de carácter legislativo o estratégico, como la Ley de emprendedores a que se ha hecho referencia anteriormente, así como directrices de carácter europeo, como la publicación del Plan de acción sobre emprendimiento 2020: Relanzar el espiritu de empresa en Europa, que han incluido en la agenda política y económica el emprendimiento como estrategia a impulsar.

\section{Resultados}

En el análisis descriptivo sobre los términos relacionados con el emprendimiento se han obtenido un total de 239 citas correspondientes a las intervenciones de los parlamentarios de distinto signo político a lo largo de las tres legislaturas analizadas (tabla 1). La intensificación del número de citas en la última legislatura muestra la dimensión alcanzada por el discurso sobre emprendimiento, al mismo tiempo que coincide con la tramitación de la legislación sobre el tema hasta la aprobación de la Ley 14/2013. Los términos emprendimiento y emprendedor en sentido estricto son los más recurrentes (citados en un 34,7\% $y$ en un $38,1 \%$, respectivamente).

Tabla 1. Intervenciones sobre emprendimiento de los parlamentarios en el Congreso de los Diputados en las legislaturas VIII, IX y XI

\begin{tabular}{lccrrr}
\hline & Legislatura VIII & Legislatura IX & Legislatura X & Total & \multicolumn{1}{c}{$\%$} \\
\hline Emprendedor & 19 & 7 & 57 & 83 & 34,7 \\
Emprendedores & 0 & 0 & 33 & 33 & 13,8 \\
Emprender & 0 & 0 & 8 & 8 & 3,3 \\
Emprendimiento & 5 & 9 & 77 & 91 & 38,1 \\
Emprendedor (de responsabilidad limitada) & 0 & 0 & 13 & 13 & 5,4 \\
Emprendedor/Emprendimiento (social) & 0 & 0 & 5 & 5 & 2,1 \\
Emprendedores/Emprendimiento (colectivos) & 0 & 0 & 4 & 4 & 1,7 \\
Emprendeduría & 0 & 0 & 1 & 1 & 0,4 \\
Emprendizaje & 0 & 0 & 1 & 1 & 0,4 \\
Totales & 24 & 16 & 199 & 239 & \\
$\%$ & 10,0 & 6,7 & 83,3 & 100,0 & 100,0 \\
\hline
\end{tabular}

Fuente: elaboración propia a partir del Diario de Sesiones del Congreso de los Diputados. 
Gráfico 1 y 2. Coocurrencia de los códigos emprendimiento y emprendedor con otros códigos del discurso parlamentario $\left(n^{\circ *}\right)$
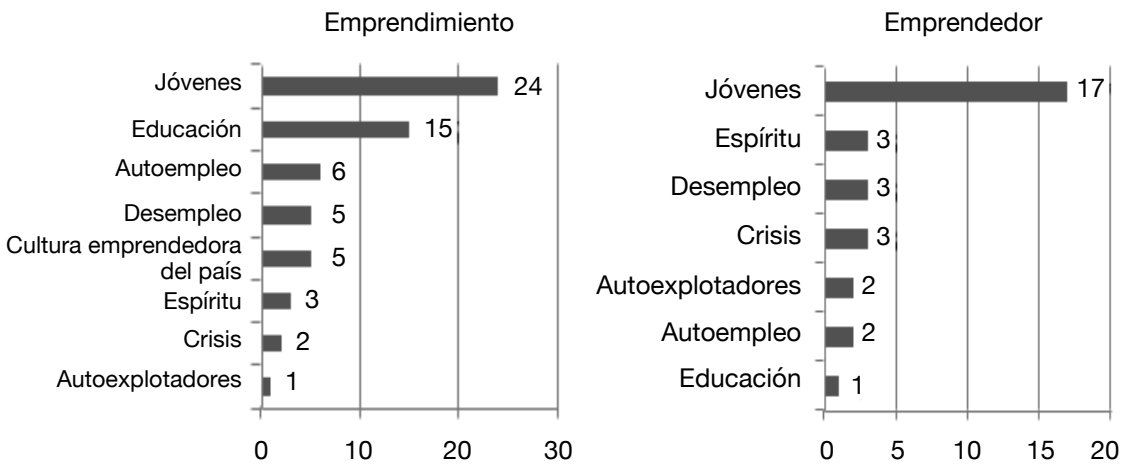

* Número de veces que coinciden los códigos en los distintos fragmentos del discurso.

Fuente: elaboración propia a partir del Diario de Sesiones del Congreso de los Diputados.

\subsection{Análisis de coocurrencia y redes semánticas}

El análisis de coocurrencia pone en relación los códigos coincidentes en los distintos fragmentos del discurso. En este caso, indica de qué otros términos se habla cuando se hace referencia a emprendimiento y a emprendedor. Como se pone de manifiesto en los gráficos 1 y 2, existe una vinculación entre estos conceptos y el de jóvenes (en 24 ocasiones coincidente con el término emprendimiento y en 17 con emprendedor), un colectivo al que va dirigido en su mayor parte el discurso sobre emprendimiento.

Asimismo, aparece una coincidencia frecuente entre los términos educación y emprendimiento. Ambos se encuentran vinculados con el código desempleo (en mayor medida, en relación con el emprendimiento), al igual que con el de autoempleo, una vinculación que muestra el sentido otorgado a la acción de emprender, estrechamente relacionada con el problema del paro y el contexto de "crisis". Los códigos espiritu emprendedor y cultura emprendedora, que aparecen en el discurso connotados de un sentido de carencia, presentan una menor coocurrencia, aunque su frecuencia en el discurso parlamentario sobre el tema es importante (en 23 ocasiones el primer término y en 19 el segundo).

La coocurrencia entre los términos analizados y la posición de gobierno del parlamentario (gráficos 3 y 4) evidencia el peso del discurso sobre emprendimiento entre los partidos de la oposición aunque, como pondrá de manifiesto el análisis interpretativo, entre esta última adquiere distintos sentidos, en unas ocasiones reivindicativo y en otras escéptico, especialmente cuando se hace referencia a las acciones gubernamentales en la promoción del emprendimiento.

Estableciendo el término emprendimiento como núcleo de significado ${ }^{10}$ del presente estudio, el análisis de redes semánticas permite visualizar las

10. Con el significado que le otorga Barthes (1974: 17) a los «núcleos de sentido» como unidades narrativas mínimas que componen la comunicación. 
Gráfico 3 y 4 . Coocurrencia de los códigos emprendimiento y emprendedor con posición de poder del discurso parlamentario $\left(\mathrm{n}^{\circ *}\right)$

Emprendimiento

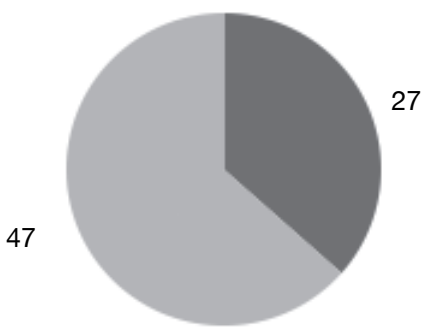

Gobernando

Oposición

27
75

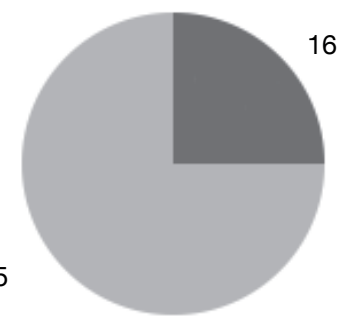

Gobernando

Oposición

* Número de veces que coinciden los códigos en los distintos fragmentos del discurso.

Fuente: elaboración propia a partir del Diario de Sesiones del Congreso de los Diputados.

relaciones establecidas entre dicho término y otras variables, tales como la ideología y el grupo parlamentario de los intervinientes en el discurso. Estas variables, junto con la posición de poder, guiarán el análisis interpretativo. El grupo parlamentario (en adelante GP) que reitera en mayor medida el término en las intervenciones de sus miembros es el GP Popular, seguido del GP Convergencia i Unió y del GP Socialista. Con menor frecuencia, aparece en los discursos de los parlamentarios del GP Vasco, GP Mixto y Esquerra (figura 1). Los resultados ponen de manifiesto la importancia que adquiere el concepto en la última legislatura (X), en la que el Partido Popular ostenta el gobierno del país y en la que se tramita la Ley 14/2013 sobre esta materia.

Figura 1. Red semántica de los códigos emprendimiento y Grupo Parlamentario

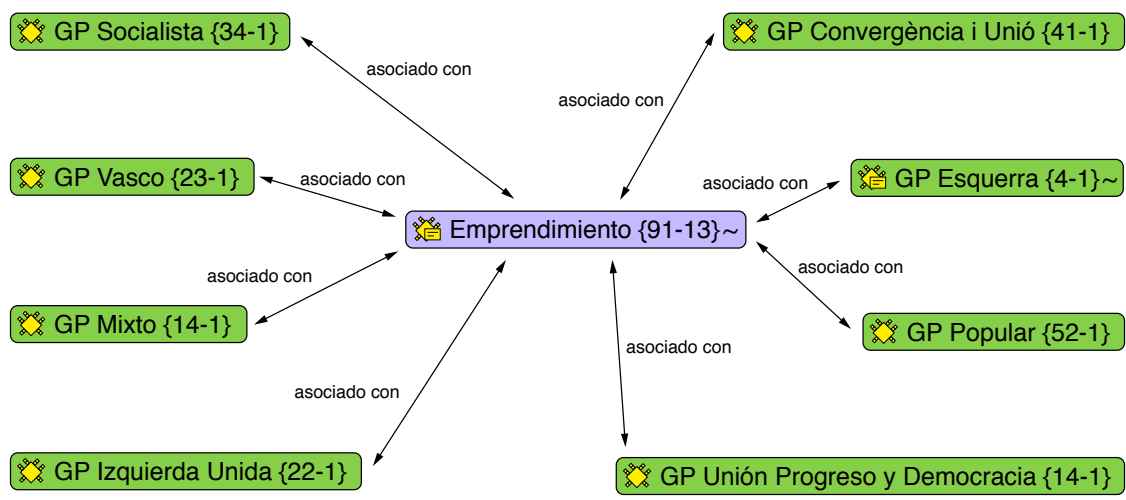


Figura 2. Red semántica de los códigos emprendimiento e ideología

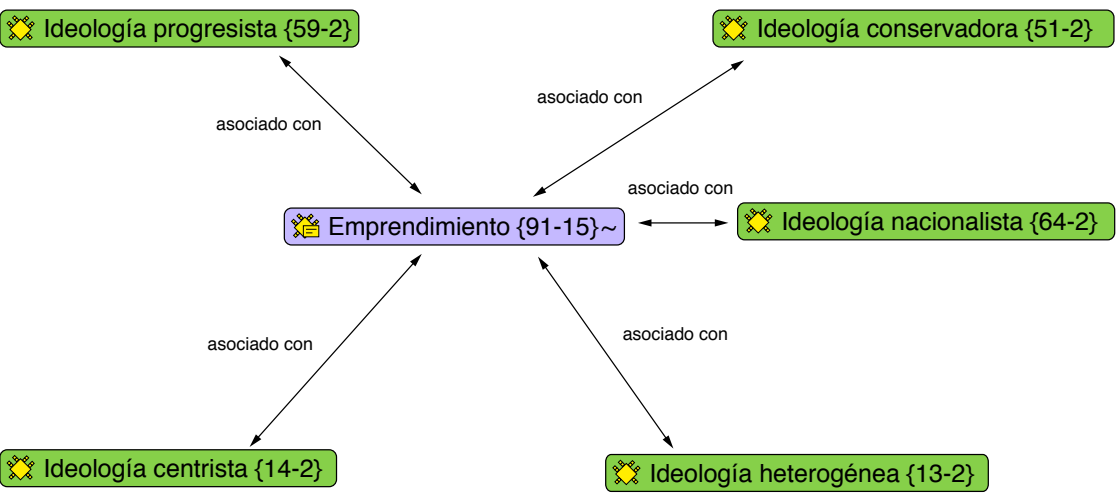

En la figura 2 están representadas las asociaciones del núcleo de significado con la ideología de acuerdo con la categorización siguiente de los GP: progresista (Socialista, Izquierda Plural y Esquerra); conservadora (Popular); nacionalista (Bloque Nacionalista Galego; catalán: CiU, y vasco: EAJ/PNV), y heterogénea (GP Mixto, y Unión, Progreso y Democracia).

Esta red permite realizar una agrupación interesante acerca de las intervenciones de los distintos grupos y muestra la importancia que adquiere el concepto en el discurso de los grupos nacionalistas, aunque sigue poniendo de manifiesto su significatividad para el grupo de ideología conservadora (Popular), con un número de citas (52) coincidentes prácticamente en cantidad con la unión de los partidos categorizados como progresistas (59).

En síntesis, el concepto de emprendimiento adquiere una especial relevancia en el discurso de los parlamentarios durante la X legislatura. Dicho concepto aparece especialmente asociado a jóvenes, educación, autoempleo y desempleo.

Las iniciativas puestas en marcha sobre esta materia por el Gobierno en 2013(especialmente la Estrategia de Emprendimiento y Empleo Joven, en la que se enmarca el Sistema de Garantía Juvenil, cuyo objetivo fue la mejora de la empleabilidad de los jóvenes, así como facilitar su entrada en el mercado de trabajo), explican en gran medida el debate parlamentario en torno a su oportunidad y efectividad. Los parlamentarios en la oposición y los de ideología conservadora y nacionalista —especialmente $\mathrm{CiU}$ - son los que en mayor medida recurren a este término en su discurso sobre el tema.

\subsection{Análisis interpretativo del discurso desde los ejes posición de gobierno $e$ ideología}

Un segundo nivel de análisis trata de interpretar la lógica narrativa del discurso recogido en el Diario de Sesiones del Congreso de los Diputados teniendo en cuenta las posiciones de los actores sociales. En este caso, se trata de decodi- 
ficar los símbolos que aluden a este aspecto de la realidad social — que es el emprendimiento- y comprobar en qué medida se encuentra marcado por la posición de poder y por la ideología de sus actores.

La posición de poder resulta una variable de especial interés en la decodificación del significado del emprendimiento. El análisis muestra un discurso en clave positiva emitido desde una posición de gobierno y un discurso crítico que procede de la oposición.

El discurso del partido en el gobierno tiene como clave enfatizar la función del emprendimiento como alternativa a los problemas de desempleo y precarización estructural del trabajo. Se trata de un discurso que maneja la premisa neoliberal, que sitúa al individuo - especialmente a los jóvenes — en el centro de la responsabilidad del crecimiento. Este discurso lleva implícita la idea de que los desempleados lo son por su poca iniciativa. Es el discurso del Partido Popular en el gobierno en la X legislatura:

La estrategia de emprendimiento y empleo responde a la voluntad firme del Gobierno de abordar de forma urgente y decidida el problema del desempleo juvenil. (Báñez, GP Popular, 260313, página 7)

La utilización en el discurso de términos connotados positivamente, tales como valientes, riqueza of futuro junto a autoempleo, emprender y emprendedores ejemplifica el uso de la estrategia de activación que responsabiliza al individuo, ya no solo de su futuro, sino del de su país:

Estamos haciendo lo que tenemos que hacer, apoyar el empleo de los jóvenes, pero también dándoles oportunidades para que se animen, a esos que son valientes que quieren emprender por su cuenta, a iniciar una actividad económica, a los jóvenes emprendedores, con una batería de medidas que también lo harán posible, porque el autoempleo es el camino de las grandes empresas, de la riqueza y del empleo futuro de nuestro país. (Bánez, GP Popular, 270213, página 20)

No obstante, el protagonismo otorgado al emprendedor trasciende la ideología y el partido para instalarse en el imaginario colectivo del partido en el poder. De nuevo la utilización del emprendimiento junto a términos identificados con la activación permanente (dinámico, cambio, progreso, movilidad social, crecimiento) marca una estrategia discursiva cuyo efecto sociolingüístico es la segmentación de los individuos en función de su protagonismo o no en un proyecto emprendedor. Es el caso del GP Socialista en la VIII legislatura:

Ya en el presente y en el futuro inmediato la economía española va a tener como protagonistas a aquellas personas que desarrollan un proyecto emprendedor; estas forman un colectivo dinámico, exigente y muy abierto al cambio y al progreso, además contribuyen de un modo excepcional a la movilidad social y al crecimiento. El Gobierno confía también de una forma muy especial en los jóvenes y en los emprendedores de este país, porque queremos que se reconozca su esfuerzo y su labor. (Clos i Matheu, GP Socialista, 210307, página 12198) 
Señorías, la sociedad está cambiando y es necesario preparar a nuestros jóvenes para una sociedad en la que van a tener que ser más que nunca actores de su vida profesional [...] Nadie duda de que el fomento del espíritu emprendedor constituye un elemento esencial para favorecer la productividad y la creación de empleo. (Tomás, GP Socialista, 270606, página 9471)

En la construcción del discurso, la reiteración y la retórica en torno a la educación en el nuevo paradigma del emprendimiento y la cultura que lo acompaña, desempeñan un papel clave, especialmente desde una posición de gobierno, una postura que se torna reivindicativa entre los partidos de la oposición, como se observará al analizar el discurso crítico del GP Socialista en la IX legislatura:

[...] Tenemos que abordar un cambio radical de nuestra cultura colectiva en todo aquello relacionado con el ámbito del emprendimiento y del autoempleo, no solo para acceder al mercado de trabajo, sino también para contribuir de forma decidida a la nueva economía que seguro construiremos tras la crisis y con la recuperación económica. (Luena, GP Socialista, 060509, página 16)

La respuesta a propuestas como esta es el escepticismo desde partidos de la oposición, como es el caso de diputados del GP Popular, en este momento en la oposición en la misma legislatura:

Su proposición inicial era fomentar y educar en la iniciativa emprendedora, y suena a tan poco que realmente no creemos que la situación que vive la juventud emprendedora de España se merezca este intento de manipulación. Los jóvenes empresarios, señores socialistas, saben lo que quieren, lo saben y nos lo hacen llegar a todos. (Uriarte, GP Popular, 060509, página 16)

La posición de gobierno determina el sentido del discurso que, cuando se ostenta el poder, adopta los argumentos relativos a la carencia de espíritu emprendedor y la necesidad de fomentar medidas que lo incentiven de tal forma que constituya la vía principal de creación de empleo. Se trata de un discurso construido a partir de códigos cuyo efecto es la transmisión de la idea de déficit y carencia individual (de espíritu emprendedor), a ello responde la aparición de términos tales como funcionarios o defraudaba. Sin embargo, en la oposición no se vislumbra como solución. Así se pone de manifiesto cuando el GP Popular interviene desde una posición de gobierno en la X legislatura:

Si preguntabas ya a los adolescentes, o ya no digo más, a los universitarios, en su inmensa mayoría querían ser funcionarios. Algunos apostaban: yo quiero ser abogado del Estado o quiero ser diplomático, si estabas en el campo universitario $[\ldots]$ pero sin duda a mí me defraudaba bastante pensar en un país donde muy pocos se manifestaban con ese espíritu emprendedor que, insisto, hace que los países despeguen, sean punteros y además tengan algo que es fundamental: una actividad económica asentada en unos pilares de grandes valores de cultura empresarial. (Álvarez, GP Popular, 120314, página 3) 
En este argumento insiste un parlamentario del mismo grupo en dicha legislatura:

Señor ministro, la iniciativa emprendedora y el espíritu emprendedor de un país son aspectos clave para su desarrollo económico. En España esta iniciativa emprendedora entre los jóvenes no es habitual [...] Es necesario por tanto contribuir a este fomento del empleo joven desde todas las direcciones posibles. (Ares, GP Popular, 280514, página 21)

El emprendimiento se une de forma indisociable al empleo, al desarrollo y a la riqueza en la retórica argumental de los partidos en el gobierno, independientemente de su signo político (legislatura X con el Partido Popular en el gobierno y IX con este mismo partido en la oposición en las citas siguientes):

Para nosotros los auténticos protagonistas de esa creación de empleo son precisamente los emprendedores, pero el emprendedor entendido en el amplio sentido de la palabra. (Madrazo, GP Popular 250713, página 17)

En ese nuevo modelo competitivo y moderno la iniciativa emprendedora es un elemento clave para generar empleo, riqueza y bienestar social. (Álvarez, GP Popular, 140410, página 16)

A diferencia de la postura institucional, el sentido del discurso en los grupos de la oposición adquiere un carácter eminentemente crítico que se concreta en diversos aspectos. Uno de los más importantes hace referencia a la utilización del emprendimiento como estrategia de creación de empleo, una crítica en la que coinciden parlamentarios de distintas formaciones y que adquiere un carácter marcadamente ideológico entre los parlamentarios progresistas - como es el caso de Izquierda Plural — en torno a la figura del emprendedor, que en realidad es considerado como la "víctima» de un capitalismo dominante que acaba en el individuo como responsable de su empleo (de ahí la profusión de la palabra autoempleo), por lo que resulta un «autoexplotador» de sí mismo. En este sentido se recogen los fragmentos de discurso correspondientes a la última legislatura:

Pensamos que el problema del empleo en estos momentos no depende de convertir a los trabajadores que pierden su trabajo en autoexplotadores de sí mismos, que es el concepto que desgraciadamente se da cuando se trata del emprendimiento [...]. El concepto emprendedor, visto como todo aquello que es iniciativa empresarial, nos parece positivo, pero el abuso que se está haciendo en estos momentos en este país y, especialmente, en esta Cámara del emprendedor como esa figura mágica, como esa especie de autoexplotador de sí mismo que ante la carencia de otro margen de maniobra posible decide iniciar una senda en la selva de una economía asfixiada, la verdad es que no lo podemos compartir. (Coscubiela, GP Izquierda Plural, 080513, página 24)

Este discurso crítico frente a la fórmula emprendedora desvela la realidad laboral española, marcada por la precariedad y la individualización de la 
relación profesional, especialmente entre el colectivo más joven, así como las causas estructurales que han llevado a esta situación. Los códigos que maneja este discurso transmiten esta visión: involuntario, obligado, externalización de riesgos o capitalismo dominante:

Recuerden lo que está pasando con la figura del autoemprendedor. Lo define muy bien Ulrich Beck, filósofo alemán: se está convirtiendo en el autoexplotador de sí mismo al servicio involuntario, obligado, de una estrategia de externalización de riesgos que ha puesto en marcha el modelo de capitalismo dominante que controla mercados y productos y externaliza la producción hacia abajo, donde encuentras al autoexplotador. (Coscubiela, GP Izquierda Plural, 230914, página 21)

El discurso de la oposición presenta una doble vertiente de carácter ideológico entre los partidos que se sitúan más a la izquierda de la escala (como se comprobaba en los anteriores fragmentos) y de índole más «instrumental» - como vía de crítica a la política económica del gobierno de los popularesentre los demás partidos que evidencian la distancia entre el discurso y la realidad (X legislatura):

Convertir en paradigma de la creación de empleo y de creación de riqueza el emprendimiento nos parece, desde una perspectiva fenomenológica, discutible $[\ldots]$ Lo que pasa es que el decaimiento de la contratación por las empresas ordinarias de trabajadores dependientes está provocando el florecimiento de otros instrumentos como el emprendimiento [...] Esto no puede ser un paradigma, un sustituto de la creación de empleo o del acceso al mercado de trabajo a través de la contratación, cuyo decaimiento es indudable y se está notando en las abultadas cifras de desempleo que, en contra de la opinión que usted manifiesta, no se terminan de corregir. (Olabarría, GP Vasco, 190913, páginas 4-5)

A veces da la sensación de tener un papel cuasi mágico a base de repetir muchas veces la palabra emprendedores, como si por ello fuesen a surgir. Pero hay una gran distancia entre la retórica y la realidad. (Anchuelo GP UPyD, 230413, página 19)

La denuncia sobre el abuso del término emprendimiento es una constante en el discurso parlamentario de la oposición. De nuevo la posición de gobierno, por encima de la ideología, es un factor determinante de la postura crítica, aunque es necesario matizar que entre partidos de ideología conservadora, como el Popular (estando en la oposición), no se ha observado esta postura crítica, y ha sido especialmente insistente desde una posición de gobierno en la última legislatura:

Respecto al tema de los emprendedores, a muchos les parecerá que está de moda y que ahora toca hablar de emprendedores. Nosotros nos lo hemos 
tomado muy en serio, no hablamos por hablar de emprendimiento. (Morán ${ }^{11}$, 250413, página 16)

No sé por qué tienen ustedes tanta tirria a la palabra emprendimiento, a los emprendedores, porque los que crean de verdad empleo y riqueza en cualquier país, también en España, son las empresas, los emprendedores. (Báñez, GP Popular, 260313, página 33)

En el discurso de la oposición que, como puede resultar obvio, plantea una postura crítica frente a la del Gobierno, es especialmente destacable su diagnóstico sobre la reiteración «exagerada» del concepto emprendimiento y la bondad que lo acompaña, como si la mera reiteración fuese capaz de activar la acción emprendedora. En este sentido se pronuncian parlamentarios socialistas y de UPyD en la última legislatura:

Respecto a la estrategia de emprendimiento y empleo joven en las últimas semanas parece que la palabra emprendimiento se ha convertido en una especie de fórmula mágica del Gobierno, como si por su mera repetición hasta el infinito fuese a surgir de la nada ese emprendimiento [...]. (Anchuelo, UPyD, 260313, página 18)

[...] Y por ello sabemos que las referencias al emprendimiento son — permítanme, como diríamos en gallego- abafantes; esto es, dificultan la respiración hasta el ahogo. Miren, emprendimiento hasta en la sopa, o si me lo permiten, hasta en la filosofía, donde aparece como tema central. Y dejaré que por mí hablen los filósofos, atiendan. Esto es - y aquí inicio la cita - «una muestra más del desmesurado afán que tiene el Ministerio por introducir en el currículum la ideología económica neoliberal en su versión más grosera». (Meijón, GP Socialista, 120314, página 7)

Los discursos se entrelazan y se comparten en muchas intervenciones, aunque en función de la orientación ideológica se utilicen con más profusión unos argumentos u otros. Ello determina una percepción y una descripción que son distintas de la realidad sobre el mercado de trabajo y el emprendimiento en España. El optimismo es una seña de identidad en el discurso desde el poder, a la vez que se convierte en un arma de exhibición de resultados políticos, especialmente entre los parlamentarios de ideología conservadora (legislatura X):

España es un país que está pletórico de emprendedores [...]. España es un país donde realmente se puede decir que existen esos emprendedores en cada uno de los puntos de nuestro territorio. (Montoro, GP Popular, 170713, página 10)

El desmantelamiento del discurso optimista del gobierno conservador viene por parte de la oposición, en este caso UPyD y el PNV, que inciden en dos claves del discurso crítico: el hecho de que no se emprende "por decreto" (espe- 
cialmente se enuncia el escenario normativo "caótico», al igual que los límites y sesgos de la ley de emprendimiento, como reflejan los siguientes fragmentos de discurso de la última legislatura) y el desplazamiento de las responsabilidades de la crisis de empleo desde las instituciones hasta los individuos:

Enésima propuesta sobre el apoyo a los emprendedores. Realmente hay una diferencia grande entre la realidad que tienen los emprendedores de apoyo en nuestro país y el número de iniciativas legislativas, que a veces da la sensación de tener un papel cuasi mágico a base de repetir muchas veces la palabra emprendedores, como si por ello fuesen a surgir. Pero hay una gran distancia entre la retórica y la realidad. (Anchuelo, UPyD, 230413, página 19)

Hoy en día la precarización laboral de la que el Gobierno popular es el principal culpable - se habla ya de una nueva clase social, los precaristas- está llevando a que las prestaciones sociales que se reciben sean mucho más débiles, a que estén mucho más erosionadas, y esto está provocando la quiebra de ese contrato social de la modernidad. No es casual que tomen fuerza en nuestra sociedad conceptos como la empleabilidad o el emprendizaje que sobre todo inciden en la responsabilidad de la persona individual, que incide en elementos individuales de responsabilidad frente a los estructurales o sociales. (Sánchez, GP Vasco, 120214, página 56)

El argumentario en torno al emprendimiento y las medidas - tanto económicas como legislativas - que lo acompañan alimentan la idea de que la acción está garantizada (emprendimiento) a partir de los medios (las medidas). Sin embargo, esto supone una suerte de acoplamiento entre el estímulo y la respuesta que obvia el entorno y descontextualiza el proceso emprendedor. Ello se explicita en el discurso de los parlamentarios de la oposición, tal es el caso de la siguiente intervención (legislatura X):

Creemos que el Gobierno parte de un error en el diagnóstico de la crisis. Argumentar a estas alturas que la causa de la alta tasa de desempleo juvenil hay que buscarla en algunas deficiencias de nuestro modelo de relaciones laborales y en la ausencia de mayor iniciativa emprendedora entre los más jóvenes que ha impedido el autoempleo es, por ser bondadosos, permítanme, señorías, una soberana tontería. La actividad productiva responde al pulso de la demanda. No hay actividad emprendedora que valga si no hay expectativas de realizar la producción de bienes y servicios. La orientación de la política económica en forma de austericidio es el principal enemigo de los emprendedores. (García, GP Izquierda Plural, 250713, página 11)

El discurso crítico adquiere tintes de ironía y dobles sentidos que tienen como objetivo cuestionar la política gubernamental en la dirección de impulsar al emprendimiento y al empleo joven (X legislatura):

Quiero expresar al Gobierno mi agradecimiento por el gran trabajo que está haciendo en materia de emprendimiento. Realmente cientos de miles de inmi- 
grantes están hoy emprendiendo el camino de vuelta a casa; cientos de miles de mujeres despedidas están emprendiendo la vuelta al hogar, al trabajo doméstico, a los cuidados; cientos de miles de jóvenes están emprendiendo el camino de la emigración [...] Hacen falta emprendedores, sí, pero yo diría que lo que hace falta es que haya muchos emprendedores que la emprendan a tortas sociales, porque la situación a la que estamos llegando es tremendamente grave y muy extrema. (Cuadra, GP Mixto, 140313, páginas 42-43)

El emprendimiento se convierte en un "arma arrojadiza» en manos de los parlamentarios en la oposición para cuestionar la eficacia de las medidas y, en general, de la política económica del Gobierno, especialmente en la última legislatura:

Señor ministro, cuando esta mañana ha citado a Schumpeter, yo pensaba por un momento que iba a citar a Laffer, pero no lo ha hecho. Dijeron que iban a bajar los impuestos y han subido y de qué manera, la mayor subida de la democracia. Dijeron que con ustedes iba a venir el crédito a las pymes y a los emprendedores, y en el tiempo que llevan gobernando el crédito está decreciendo a una tasa del 7\% — anteriormente se decrecía a una tasa del 2\%-. (Saura, GP Socialista, 170713, página 24)

Para terminar, el señor ministro ${ }^{12}$ citaba a Schumpeter. Una de las grandes ideas de Schumpeter era la destrucción creativa. El problema en la política económica de nuestro país es que en la parte de destrucción se ha avanzado mucho, pero en la parte creativa, como la que hoy nos ocupa, se suele ser mucho menos ambicioso. (Anchuelo, GP UPyD, 170713, página 28)

La desmitificación del emprendimiento forma parte del discurso de la oposición, de la misma forma que la reiteración sobre sus bondades lo hace del discurso desde el Gobierno, en un intento por "construir» una realidad que no tiene su reflejo en los datos sobre actividad emprendedora.

\section{Conclusiones}

El análisis sobre el discurso en torno al emprendimiento ha puesto de manifiesto la relativa indeterminación semántica del concepto. Frente a esta, el discurso político ha ido construyendo su significado en un proceso en el que la posición respecto al poder y la ideología operan como un «reductor» de dicha indeterminación.

El contexto en el que se desarrolla el discurso se ha revelado un factor explicativo por dos razones: una es de carácter temporal y la otra, de índole ideológica. En cuanto a la primera, una vez asumida la situación de crisis económica del país, es momento de soluciones, y el emprendimiento forma parte de la solución al problema más importante: el desempleo, especialmente

12. En referencia al ministro de Hacienda, Cristóbal Montoro. 
el juvenil. La intensificación de alusiones al concepto de emprendimiento en la X legislatura (en la que se aprueba legislación clave sobre la materia) prueba este hecho.

\section{Discurso e ideología}

En cuanto a la razón ideológica, el análisis ha puesto de manifiesto la recurrencia al concepto, especialmente por parte de los parlamentarios de ideología conservadora, como los del GP Popular, en una posición de gobierno en esta última legislatura. En su discurso, el emprendimiento se vincula a otros significantes tales como jóvenes, educación y autoempleo, y se reivindica como remedio a los problemas de desempleo. El emprendimiento aparece como la solución —ideológica - frente a otras alternativas. La opción es una suerte de capitalismo "proactivo" con el individuo y la iniciativa individual como protagonistas, frente a la idea de unas estrategias «reactivas» que sitúan el peso de la acción en las políticas públicas y en el Estado.

El emprendedor es identificado con el joven «dueño de su futuro», y el corolario de esta identificación es que la ausencia de «espíritu emprendedor» es la causante de los bajos niveles de empleo entre este colectivo. Ante este hecho, la educación en dicho espíritu y el fomento de la cultura emprendedora se convierten en acciones prioritarias.

Frente a esta posición, entre los parlamentarios de ideología progresista se desarrolla un discurso de carácter crítico que desvela la representación ideológica que encubre el uso del término emprendimiento (matizado, no obstante, por la posición de gobierno, como es el caso del GP Socialista cuando ha ocupado dicho cargo). En concreto, una concepción del capitalismo del ego (Beck, 2000) en el que surge la figura del empresario de sí mismo (Martínez y Amigot, 2015), aquel que descarga sobre sí la «coerción de explotación y autoopresión». Se trata de la figura del emprendedor precario o emprendeudor, un perfil que incorpora la subjetividad propia de los postulados financieros, según los cuales la asunción de costes y de riesgos es parte de la forma «de ser» de la nueva fuerza de trabajo (Moruno, 2016).

La persuasión e insistencia en el término emprendimiento, que entra de lleno en la agenda política, parece indicar una estrategia que busca «modelizar» el comportamiento. En particular, el discurso político persuade, posibilita y justifica la acción política (Lamizet, 2002), especialmente desde una posición de gobierno. Este hecho es constatado en el discurso de los parlamentarios que, desde posiciones críticas, aluden al abuso del concepto, por otra parte, poco identificado con la realidad social.

\section{Discurso y posición de poder}

La posición estratégica de gobierno marca el discurso hegemónico del emprendimiento alrededor de la idea de que los individuos van a desempeñar un papel fundamental en la creación de condiciones para que la sociedad pueda superar 
la crisis y crecer. Este discurso político vincula la noción de emprendimiento con la consecución de objetivos sociales (coincidiendo con otros estudios sobre el tema, como el de Vega, 2014). De esta forma, se consigue una neutralización del discurso crítico - en el que el emprendimiento es un concepto polémicoy la transformación de la incertidumbre de significados en una "certeza monolítica» (Larraín, 2010). Este discurso que llama a la «movilización» concuerda ideológicamente con el neoliberalismo económico, que sitúa la «carga de la prueba" o responsabilidad del crecimiento sobre el individuo. Renueva - de esta forma- el viejo esquema taylorista («Se trata de intentarlo») evocando al más actualizado espíritu emprendedor («Just do it»). El individuo ha de llegar a la meta por sí mismo. Será su responsabilidad, también, el fracaso y, con él, el de un proyecto de crecimiento económico y social.

Frente a este discurso, el argumento de la oposición suele ser crítico (practicado también por los parlamentarios de los grupos Popular y Socialista cuando se encuentran en dicha posición), aunque no es monológico, sino que adquiere un doble carácter. El análisis muestra una crítica «instrumental» que recoge la carencia de una política eficaz en la promoción de medidas a favor del emprendimiento (un discurso protagonizado por los partidos nacionalistas, especialmente de los parlamentarios de $\mathrm{CiU}$ ), a la vez que se utiliza como «arma» crítica frente a la política gubernamental (sea del signo que sea). Junto a este se observa un discurso más ideológico, como es el protagonizado por los partidos progresistas, especialmente Izquierda Plural, que «denuncia» la deriva hacia un capitalismo de individualidades en el que el emprendimiento encubre una política encaminada a la autoexplotación.

En futuros trabajos puede resultar útil realizar un análisis sobre el tema a partir de los documentos de los distintos partidos políticos, tales como programas, informes o ponencias en congresos. También será oportuno profundizar en aspectos como la representación del sujeto — especialmente el sujeto en clave económica - en el ideario político de los partidos.

\section{Referencias bibliográficas}

AJZen, Icek (1988). Attitudes, Personality and Behaviour. Chicago: Dorsey.

Alonso, Luis E. y Fernández, Carlos (2006). «Roland Barthes y el análisis del discurso». Empiria, 12, 11-35. $<$ https://doi.org/10.5944/empiria.12.2006.1131>

- (2011). «La innovación social y el nuevo discurso del Management: Limitaciones y alternativas». Arbor, 187 (752), 1133-1145. <https://doi.org/10.3989/arbor.2011.752n6009>

ANGENOT, Marc (2010). El discurso social: Los límites históricos de lo pensable y lo decible. Buenos Aires: Siglo XXI.

ARARAT, Jaime A. (2010). «La ideología del emprendimiento: Una mirada desde el análisis crítico del discurso». Ad-Minister, 17, 5-33.

BARTHES, Roland (1974). «Introducción al análisis estructural de relatos». En: BARTHES, Roland y TODOROV, Tzvetan (eds.). Analisis estructural del relato. Buenos Aires: Tiempo Contemporáneo. 
- (1990). La aventura semiológica. Paidos: Barcelona.

BECK, Ulrich (2000). Un nuevo mundo feliz: La precariedad del trabajo en la era de la globalización. Barcelona: Paidós Ibérica.

BURT, Ronald (2000). «The Network Structure of Social Capital». En: SuTTON, Robert I. y STAW, Barry M. (eds.). Research in Organizational Behavior. Greenwich, CT: JAI Press.

Calvo, Ricard y Lerma, Ignasi (2009). «Políticas activas de empleo en tiempo de crisis: Una visión crítica desde lo local». Lan Harremanak, 20-21, 227-250.

Cejudo, Guillermo (2008). Discurso y politicas públicas: Enfoque constructivista. Documento de Trabajo n. ${ }^{\circ}$ 205. Méjico: Centro de Investigación y Docencia Económicas.

Centro De Investigaciones Sociológicas (2012). Actitudes de la juventud en España hacia el emprendimiento, 2938 (marzo-abril).

Charaudeau, Patrick (2003). El discurso de la información. Barcelona: Gedisa.

COMISIÓN EUROPEA (2007). Hacia los principios comunes de la flexiguridad: Más y mejor empleo mediante la flexibilidad y la seguridad. Bruselas.

- (2013). Plan de acción sobre emprendimiento 2020: Relanzar el espíritu de empresa en Europa. Bruselas.

Consejo Europeo (1997). Estrategia Europea de Empleo. Luxemburgo.

CRESPO, Eduardo y SERRANO, Amparo (2013). «Las paradojas de las políticas de empleo europeas: De la justicia a la terapia». Universitas Psychologica, 12 (4), 1111-1124. $<$ https://doi.org/10.11144/javeriana.upsy12-4.ppee>

Diario de Sesiones del Congreso de los Diputados. Recuperado de <http://www.congreso.es/portal/page/portal/Congreso/Congreso> [Consulta: 5 octubre 2015].

Estrin, Saul; KorosteleVA, Julia y MiCKIEWICZ, Tomasz (2013). «Which institution encourage entrepreneurial growth aspirations?». Journal of Business Venturing, 28 (4), 564-580. <https://doi.org/10.1016/j.jbusvent.2012.05.001>

FAIRCLOUGH, Norman (2002). «Language in new capitalism». Discourse \& Society, 13 (2), 163-166. <https://doi.org/10.1177/0957926502013002404>

FAIRCLOUGH, Norman L. y WODAK, Ruth (1997). «Critical discourse analysis». En: VAN DijK, Teun (ed.). Discourse as social interaction. Londres: Sage.

GARCíA, Domingo (2006). «Discurso oficial y adversidad: Implantación de la modalidad emprendedora en México». Trayectorias, 21 (8), 139-151.

GARDNER, John (1995). Self-Renewal: The Individual and the Innovative Society. Nueva York: WW Norton \& Company.

GEM (2015). Informe GEM España 2015. Recuperado de <http://www.cise.es/wpcontent/uploads/InformeGEM2015.pdf> [Consulta: 26 diciembre 2016].

Gertler, Meric y Wolfe, David (2002). «Innovation and Social Learning: An Introduction». En: WOLFE, David y GerTler, Meric (eds.). Innovation and Social Learning: Institutional Adaptation in an Era of Technological Change. Basingstoke: Palgrave MacMillan.

GiBB, Allan y RitCHIE, John (1982). «Understanding the process of starting small businesses». European Small Business Journal, 1 (1), 26-46. <https://doi.org/10.1177/026624268200100102>

GirAUDEAU, Martin (2007). "Le travail entrepreneurial, ou l'entrepreneur schumpetérien performé». Sociologie du Travail, 49, 330-350. <https://doi.org/10.1016/j.soctra.2007.06.025> 
Guerrero, Néstor y VeGA, María J. (2014). «Reflexiones teóricas y metodológicas sobre política, ideología y discurso». V Congreso Uruguayo de Ciencia Política. Montevideo.

Hagen, Evertt (1968). The economics of development. Irwin Press: Dorsey.

JONES, Campbell y SPICER, André (2009). Unmasking the Entrepreneur. Cheltenham: Edward Elgar.

LAmizet, Bernard (2002). «Semiótica de lo político». DeSignis, 2, 97-108.

LARraín, Jorge (2010). El concepto de ideología: Postestructuralismo, Postmodernismo y Postmarxismo. Santiago de Chile: LOM Ediciones.

MartíneZ, L. y Amigot, P. (2015). «Una aproximación al discurso europeo sobre la educación emprendedora a nivel superior: ¿Cambiar la mentalidad para generar empleo?». Arxius, 32, 99-110.

MazzUCATO, Mariana (2014). El Estado emprendedor: Mitos del sector público frente al privado. Barcelona: RBA.

MCClelland, David C. (1961). The achieving society. Nueva York: The Free Press.

Ministerio De Empleo Y SEguridad Social (2013). Estrategia de emprendimiento y empleo joven 2013-2016.

- (2013). Plan Nacional de Implantación de la Garantía Juvenil en España.

Moruno, Jorge (2016). La fábrica del emprendedor: Trabajo y política en la empresamundo. Madrid: Akal.

Olaz, Ángel (2008). La entrevista en profundidad. Oviedo: Septem Ediciones.

OrTiz, Pilar (2013). "Cambios en la legislación laboral y contratación temporal en España». Cuadernos de Relaciones Laborales, 31 (1), 141-165. <https://doi.org/10.5209/rev_crla.2013.v31.n1.41644>

- (2014). «El trabajo a tiempo parcial: ¿Una alternativa para la mujer en tiempos de crisis?». Sociología del Trabajo, 82, 73-92.

PereirA, Fernando (2007). «La evolución del espíritu empresarial como campo de conocimiento: Hacia una visión sistémica y humanista». Cuadernos de Administración, 20 (34), 11-36.

Ruiz, José; Cabello, Carmen y Medina, Raúl (2014). «La Ley de Emprendedores y la creación de empresas: Una visión desde el observatorio GEM». Universia, 8 (3), 45-61.

Santamaría, Elsa y Serrano, Amparo (2016). Precarización e individualización del trabajo: Claves para entender y transformar la realidad laboral. Barcelona: Editorial UOC.

SCHumpeter, Joseph A. (1957). Teoría del desenvolvimiento económico. México: Fondo de Cultura Económica.

SERrano, Amparo y CRESPO, Eduardo (2002). «El discurso de la Unión Europea sobre la sociedad del conocimiento». Revista Española de Investigaciones Sociológicas, 97, $189-207$. <https://doi.org/10.2307/40184369>

Serrano, Amparo; Fernández, Carlos J. y Artiaga, Alba (2012). «Ingenierías de la subjetividad: El caso de la orientación para el empleo». Revista Española de Investigaciones Sociológicas, 138, 41-62. $<$ https://doi.org/10.5477/cis/reis.138.41>

VAn Dijk, Teun (1999). "El análisis crítico del discuso». Anthropos, 186, 23-36. $<$ https://doi.org/10.14409/texturas.v1i1.2769>

VeCiAnA, José (2005). La creación de empresas. Barcelona: La Caixa.

VEGA, María J. (2014). Discurso político y construcción social de sentido. Nociones de emprendedor-emprendimiento en el programa de gobierno y mensaje 21 de 
mayo 2012 de Sebastián Piñera, en Trayectos teóricos en semiótica. Recuperado de <http://aucip.org.uy/docs/v_congreso/ArticulospresentadosenVcongresoAucip/ AT15-PoliticaCulturaIdeologiaDiscursos/Guerrero-Vega_ReflexionesTeoricas. pdf> [Consulta: 14 septiembre 2015].

Weber, Max (1999). La ética protestante y el espíritu del capitalismo. Barcelona: Península. 